\title{
Blood Transfusion in Premature or Young Infants with Polyagglutination and Activation of the T Antigen
}

\section{C.P. Engelfriet \\ H.W. Reesink}

It is known from the literature that severe haemolytic transfusion reactions may occur in premature infants or young children with an activated $\mathrm{T}$ antigen when they are transfused with blood or plasma-containing blood components from donors with strong anti-T. It has come to our attention that in some transfusion centres, the provision of blood or blood components for such infants or children is considered to be a transfusion problem. It seemed worthwhile to obtain information on the subject via a short International Forum.

The following questions were submitted to 18 colleagues who might have experience with this problem. Unfortunately, we have been able to obtain only 8 answers.

(1) Do you screen infected infants for polyagglutination and $\mathrm{T}$ activation or only infants with necrotizing enterocolitis or none at all?

(2) Do you think that there is a need for blood banks/transfusion centres to screen for donors with anti-T in low titres?

(3) Do you think that blood banks/transfusion centres should be able to provide blood or plasma-containing components with anti-T in low titre?

Question 1: In two centres, children with necrotizing enterocolitis are routinely screened for polyagglutination and $\mathrm{T}$ activation (Martin-Vega, Gibson). In two other centres, infants are screened in selected cases: either because an infant with sepsis or necrotizing enterocolitis has symptoms of increased haemolysis (Strauss) or because, after a transfusion with plasma-containing components, an infant has symptoms of increased haemolysis or there is failure to achieve the expected posttransfusion haemoglobin level (Luban). In the other centres, no screening is done at all because no cases of haemolysis after transfusion due to T activation have been seen in years.

Question 2: A stock of fresh frozen plasma with anti-T in low titre is available in one centre and children with $\mathrm{T}$ activation are only transfused with washed red cells. However, for platelet transfusions donors are not selected (Gibson). No stock of fresh frozen plasma or a special panel of donors with anti- $\mathrm{T}$ in low titre are available in any of the other centres, but the formation of such a stock or panel is advocated by one contributor (MartinVega). In two centres, donors with low-titre anti-T are selected ad hoc prior to transfusion of infants with activated T (Strauss, Luban). Incidentally, there does not seem to be a clear definition of low-titre anti-T, but in one centre anti- $\mathrm{T}$ with a titre not greater than 1 in saline is considered suitable [Strauss, pers. commun.].

Question 3: As can be concluded from the answers to question 2, those contributors to the Forum who see cases of increased haemolysis due to $\mathrm{T}$ activation are of the opinion that this should indeed be the case, although it is mostly felt that such donors can be selected when transfusion is in fact needed.

In conclusion, although not many contributions to the Forum were obtained, it seems clear that problems in infants or young children due to $\mathrm{T}$ activation are rare. The provision of blood or plasma-containing components for such children is considered a transfusion problem in only a few centres. Routine screening for $\mathrm{T}$ activation is not done anywhere, but selected cases are screened in three centres. A problem in selecting cases for screening, when no transfusion problems have occurred, seems to us the absence of anti-T in infants and very young children who therefore may have strong $\mathrm{T}$ activation without any symptoms of increased haemolysis.

No panels of fresh frozen plasma or donors with anti-T in low titre are available, such donors rather being selected ad hoc. One reason is that it is not known whether the titre of anti-T is stable over time.

\author{
Prof. C.P. Engelfriet \\ Central Laboratory of the Netherlands \\ Red Cross Blood Transfusion Service \\ PO Box 9137 \\ NL-1006 AC Amsterdam (The Netherlands) \\ H.W. Reesink, MD, PhD \\ Red Cross Blood Bank Amsterdam \\ PO Box 9137 \\ NL-1006 AC Amsterdam (The Netherlands)
}

\section{Ronald G. Strauss}

Question 1: There is no group of infants that we routinely screen for polyagglutination and $\mathrm{T}$ activation. We interact with the neonatologists and selectively screen symptomatic infants by incubating their red blood cells (RBCs) with a commercial panel of lectins (Arachis hypogaea, Salvia sclarae, Salvia horminum, Glycine soja) and fresh plasma from AB0-compatible adults. For controls, both negative and positive (neuraminidase-treated) RBCs are included. Reactions are read only macroscopically with an estimate of strength (1+ to 4+).

The rationale for selective, rather than routine, screening is based on the following:

\begin{tabular}{ll}
\hline KARGER & ( ) 1999 S. Karger AG, Basel \\
Fax +41 61 306 12 34 & 0042-9007/99/0762-0128 \$17.50/0 \\
$\begin{array}{l}\text { E-Mail karger@ karger.ch } \\
\text { www.karger.com }\end{array}$ & $\begin{array}{l}\text { Accessible online at: } \\
\text { http://BioMedNet.com/karger }\end{array}$
\end{tabular}


(1) RBCs from $10-15 \%$ of apparently healthy neonates may exhibit $\mathrm{T}$ activation [1]; (2) up to $30 \%$ of infants with necrotizing enterocolitis may exhibit $\mathrm{T}$ activation - yet only a minority of them develop clinically significant hemolysis [2-5] - and (3) locally, we simply do not see clinically evident hemolysis due to $\mathrm{T}$ activation in our high-risk infants with sepsis or gastrointestinal disorders with a necrotic bowel - despite admitting approximately 140 neonates annually with birth weight $<1.5 \mathrm{~kg}$. Thus, we carefully observe high-risk infants and evaluate them promptly when clinical evidence for $\mathrm{T}$ activation appears.

Question 2: The need to screen donors for anti-T depends on local infant needs (expanded in the following paragraph) and on the philosophy of individual blood centers (i.e. whether it is preferred to screen donors simultaneously with pretransfusion compatibility testing for individual infants or whether a group of donors with low-titre anti-T should be assembled for use later when needed). Our policy, when selecting plasma-containing components for infants with clinically significant $\mathrm{T}$ activation, is to screen donors immediately before transfusion using a minor cross-match. The minor cross-match is relatively insensitive (i.e. donors with weak anti-T or infant RBCs with mild $\mathrm{T}$ activation may be missed), but most episodes of clinically significant hemolysis occur in the setting of potent anti- $\mathrm{T}$ and/or severe $\mathrm{T}$ activation [2-5]. Moreover, screening donors against neuraminidase-treated 'positive control' RBCs is too sensitive, as all donor sera react and are incompatible. We have made no effort to assemble a group of low-titre anti-T donors to be available for future use as needed because of uncertainties regarding how potent anti- $\mathrm{T}$ is over time in any one donor (i.e. do titer, thermal amplitude, affinity etc. remain constant or change?).

Question 3: Yes, for infants with clinically significant hemolysis due to $\mathrm{T}$ activation. Probably, for infants without clinical evidence of hemolysis but with laboratory documentation of strong $\mathrm{T}$ activation. No, as a routine transfusion product for infants with high-risk disorders in which $\mathrm{T}$ activation is neither evident clinically nor documented by $\mathrm{RBC}$ testing. As a final caveat - although transfusion of washed RBCs is traditional - it is reasonable to consider transfusing $\mathrm{RBCs}$ preserved in extended storage media, from which nearly all plasma has been either removed or greatly diluted, particularly in programs designed to limit donor exposure [6].

\section{References}

1 Wahl CM, Herman JH, Shirey RS, Kickler TS, Ness PM: T activation of maternal and cord blood. Transfusion 1989;29:635-637.

2 Rodwell R, Tudehope DI: Screening for cryptantigen exposure and polyagglutination in neonates with suspected necrotizing enterocolitis. J Paediatr Child Health 1993;28:16-18.

3 Novak RW, Abbott AE Jr, Klein RL: Tcryptantigen determination affects mortality in necrotizing enterocolitis. Surg Gynecol Obstet 1993;176:368-370.

4 Klein RL, Novak RW, Novak PE: T-cryptantigen exposure in neonatal necrotizing enterocolitis. J Pediatr Surg 1986;21:115-118.

5 Williams RA, Brown EF, Hurst D: Transfusion of infants with activation of erythrocyte T antigen. J Pediatr 1989;115:949-953.

6 Strauss RG, Burmeister LF, Johnson K, James T, Miller J, Cordle DG, Bell EF, Ludwig GA: AS-1 red cells for neonatal transfusions: A randomized trial assessing donor exposure and safety. Transfusion 1996;36:873-878.

\section{Ronald G. Strauss, MD}

University of Iowa Hospitals and Clinics Department of Pathology, 153A MRC Iowa City, IA 52242-1182 (USA)

Tel. +1 (319)335 8150, Fax +1 (319)335 6555

E-Mail ronald-strauss@uiowa.edu

\section{Naomi L.C. Luban}

$\mathrm{T}$ antigen activation occurs in infants, children and adults. In the infant, symptoms and signs can be marked by the complex clinical and laboratory findings associated with sepsis and/or the postsurgical period. Of particular concern are infants with necrotizing enterocolitis (NEC) which is often associated with gram-negative sepsis, especially from Clostridium species [1].

Passive transfusion of anti- $\mathrm{T}$ in the form of fresh frozen plasma, unwashed red blood cells or platelets may produce hemolysis. Hemolysis may range from none to fulminant and fatal [1-5].

\section{Incidence}

Williams et al. [1] reported a frequency of $\mathrm{T}$ activation as a laboratory phenomenon in $0.6 \%$ or 10 of 1,672 infants tested. When infants with NEC were analyzed as a subgroup, $\mathrm{T}$ activation was reported in $11 \%$, increasing to $28 \%$ in the subgroup requiring surgical intervention. In another prospective study of infants with suspected NEC, $17(27 \%)$ had evidence of $\mathrm{T}$ antigen activation. Those infants had Clostridium cultured from blood, peritoneal fluid or stool in $88 \%$ of cases and were more likely to have intestinal perforation at laparoscopy [6]. As the mortality rate for very-low-birth-weight infants has decreased in recent years, the incidence of NEC has increased. It has been estimated that NEC may develop in 1-10\% of infants hospitalized in neonatal intensive-care units, with $90 \%$ of cases occurring in premature infants [7]. If NEC is common in infants who require plasma-containing products for iatrogenic blood loss or therapeutic need, then the phenomenon of $\mathrm{T}$ activation should be more than just a laboratory oddity.

\section{Clinical Presentation}

Tests to identify $\mathrm{T}$ antigen activation should be performed in neonates who have received red blood cells or plasma-containing components and who have evidence of (1) intravascular hemolysis with hemoglobinuria, hemoglobinemia and hypohaptoglobinemia or (2) unexplained failure to achieve the expected posttransfusion hemoglobin increment.

However, one must be cognizant that intravascular hemolysis can be due to other causes [8].

Anemia as a consequence of hemolysis is common in the newborn period and results from multiple causes. In adults, hemolysis is classically diagnosed by the presence of a rapidly decreasing hemoglobin level, reticulocytosis in the absence of hemorrhage and abnormal red blood cell morphology with schistocytes, spherocytes and anisocytosis. In addition, one may see an increase in free plasma hemoglobin with hypohaptoglobinemia and hemoglobinuria. Alternatively, if breakdown has occurred in the reticuloendothelial system, hyperbilirubinemia is seen. These laboratory tests are of limited benefit in diagnosing hemolysis in the newborn. For example, newborns who have extensive blood sampling at $10 \%$ of blood volume or who are receiving fluids and diuretics that cause intravascular fluid shifts have fluctuating hemoglobin levels. Reticulocyte counts in newborns are higher than in adults and have a wide range, limiting the usefulness of the test. In normal newborns, serum haptoglobin levels are reduced, and in premature infants, serum haptoglobin levels are markedly reduced, predisposing the infant to hemoglobinuria without intravascular hemolysis. Marked elevations of free plasma hemoglobin and persistent hemoglobinuria would identify the newborn with marked intravascular hemolysis but would miss the patient with mild hemolysis. Indirect hyperbilirubinemia is neither specific for nor 
diagnostic of hemolysis, as there are many causes of hyperbilirubinemia in the newborn. The unusual and rapid development of hyperbilirubinemia during the first $24 \mathrm{~h}$ of life warrants the investigation into the cause; hemolytic disease may be one cause.

\section{Diagnosis}

Infants whose clinical presentation indicates that they are at risk for NEC should be suspected of $\mathrm{T}$ antigen activation if they have suboptimal increases in hemoglobin and hematocrit with evidence of hemolysis on smear [5]. Some investigators have recommended that all infants who develop hemolysis after transfusion should be studied [9]. Laboratory evidence of cryptantigen exposure may be suspected in infants who have discrepancies in forward and reverse blood grouping or who have inconsistencies in blood group and type over time. Standard cross-matching techniques may not detect activation unless mixed-field agglutination is seen.

In the USA, the diagnosis of $\mathrm{T}$ activation is particularly problematic for three reasons. Firstly, major and minor cross-matching of blood is rarely performed. While the minor cross-matching of neonatal T-activated red cells with donor anti-T-containing serum may show agglutination, this safeguard against release of anti-T-containing components does not exist. Secondly, specific and sensitive tests that use peanut lectin and those from Arachis hypogaea and Glycine soja, while relatively simple to perform, are not routinely available in most hospital transfusion services. Thirdly, the diagnosis of T activation is difficult when monoclonal $\mathrm{AB} 0$ typing reagents are used; the polyagglutinability of T-transformed red blood cells or disagreement in forward and reverse groupings may not be seen.

\section{Management}

Infants with cryptantigen exposure from NEC or postsurgical sepsis require prompt treatment with antibiotic therapy that affords broad anaerobic coverage. Infants with brisk, ongoing hemolysis with hemoglobinuria require exchange transfusion with plasma-reduced components. Such components may include washed packed cells and packed cells suspended in plasma protein fraction, salineadditive solutions or albumin. Some infants may require plasma, cryoprecipitate and platelet concentrates for treatment of coagulopathies. Meeting these infants' needs is particularly problematic. Those infants with mild $\mathrm{T}$ antigen activation may be treated without difficulty; those with strong reactivity may well develop hemolysis while receiving the components. Some institutions have developed specific protocols to screen all infants prior to receipt of plasma components, and they use a specialized protocol for those who demonstrate marked $\mathrm{T}$ activation. Washed platelets, washed red blood cells and plasma from donors with low anti-T titers are part of such a protocol [1]. The advisability of such broad-based screening has been wisely questioned [9], and the availability of lowtiter anti-T plasma is limited in the USA.

\section{Prevention}

Hemolysis associated with $\mathrm{T}$ activation may occur independently of transfusion with anti-T plasma and may well be the result of sepsis and disseminated intravascular coagulation; this cannot be prevented. Alternatively, hemolysis induced by anti-T-containing plasma can be prevented by avoidance of plasma-containing components or use of low-titer anti-T plasma when it is required for treatment of coagulation deficiencies.

Infants with septicemia and NEC who need support with plasma-containing blood components constitute a population who might benefit from a lectin panel or minor cross-match in advance of a specific transfusion. Routine periodic screening of neonates would be costly and would yield few susceptible infants.

\section{References}

1 Williams RA, Brown EF, Hurst D, Franklin LC: Transfusion of infants with activation of erythrocyte T antigen. J Pediatr 1989;115:949953.

2 Novak RW: Bacterial induced red blood cell alterations duplicating necrotizing enterocolitis. Am J Dis Child 1984;138:183-185.

3 Squire R, Kiely E, Drake D, Lander A: Intravascular haemolysis in association with necrotizing enterocolitis. J Pediatr Surg 1992; 27:808-810.

4 Placzek MM, Gorst DW: T activation hemolysis and death after blood transfusion. Arch Dis Child 1987;62:743-744.

5 Marshall CR, Barr AL, French NP, Lown JA, Knowles S: A fatal case of necrotizing enterocolitis in a neonate with polyagglutination of red blood cells. J Paediatr Child Health 1993; 29:63-65.

6 Klein RL, Novak RW, Novak PE: T-cryptantigen exposure in neonatal necrotizing enterocolitis. J Pediatr Surg 1986;21:1155-1158.
7 Vanderhoof JA, Zach TL, Adrian TE: Gastrointestinal disease; in Avery GB, Fletcher MA, MacDonald MG (eds): Neonatology: Pathophysiology and management of the newborn. Philadelphia, Lippincott, 1994, pp 605-629.

8 Boothe G, Brecher ME, Root M, Robinson J, Haley R: Acute hemolysis due to passively transfused high-titer anti-B causing spontaneous in vitro agglutination. Immunohematology 1995;11:43-45.

9 Rodwell R, Tudehope DI: Screening for cryptantigen exposure and polyagglutination in neonates with suspected necrotizing enterocolitis. J Paediatr Child Health 1993;29:16-18.

Naomi L.C. Luban, MD

Vice Chairman

Director of Transfusion Medicine/

Quality Assurance

Department of Laboratory Medicine

Children's National Medical Center

111 Michigan Ave., NW

Washington, DC 20010 (USA)

Fax +1 (202) 8842007

Voicemail +1 (202) 8845292

E-Mail nluban@cnmc.org

\section{Elizabeth Letsky \\ Neena Modi}

\section{Background}

The erythrocyte $\mathrm{T}$ antigen is present on all human erythrocytes but is not expressed unless $\mathrm{N}$-acetyl-neuraminic acid is removed from the red cell membrane by neuraminidase. Neuraminidase is produced by a large number of microbiological agents including bacteria, viruses and protozoa. In vivo $\mathrm{T}$ antigen activation has been reported in association with anaerobic, particularly clostridial sepsis, as well as other severe infections. Anti-T is an IgM haemolytic and agglutinating antibody. It is detectable in adult plasma but not in early infancy [1]. Sporadic case reports have suggested that neonates, especially with necrotizing enterocolitis, are at risk of activation of the $\mathrm{T}$ antigen and haemolysis precipitated by blood transfusion, and this has raised the question of whether it is necessary to provide low-titre anti-T blood products to neonates.

Novak et al. [2] go further and suggest that screening for $\mathrm{T}$ antigen activation is of diagnostic and prognostic importance in necrotizing enterocolitis. However, these authors used a definition of haemolysis that is highly questionable in ill, newborn babies, namely a decrease in serum haemoglobin of $2 \mathrm{~g} / \mathrm{dl}$ or an increase in serum bilirubin of more than $72 \mu \mathrm{mol} / 1$ in a 24 -hour period. 
Several authors have expressed scepticism about the haemolytic potential of anti- $\mathrm{T}$ in neonates [3].

\section{Current Practice}

It is standard current practice in neonatal medicine to transfuse red cells as red cell concentrate or in SAG-M optimum additive solution, which contain minimal or negligible quantities of plasma. However, neonatologists vary in their use of fresh frozen plasma and in their choice of product for exchange transfusion. Our practice is based at two associated tertiary referral neonatal intensivecare units at the Hammersmith Hospital and Queen Charlotte's Hospital. These serve an obstetric population of approximately 5,000 deliveries and admit around 650 infants - inborn, referred and neonatal surgical cases to the neonatal intensive-care units annually.

Red cell transfusions are provided to our neonates in the form of packed red cells, and there is therefore only a very small volume of plasma administered concurrently. However, we are liberal in our use of fresh frozen plasma in ill infants and, in situations requiring volume support, prefer its use over that of human albumin solution. We use whole blood for exchange transfusions.

We do not screen any infants for polyagglutination and $\mathrm{T}$ antigen activation, nor have we ever done so. Our regional blood transfusion service neither supplies low-titre anti-T products nor reports a demand from other neonatal intensive-care units [M. Contreras, pers. commun.].

The suggestion that low-titre anti-T products are necessary in cases of necrotizing enterocolitis is illogical, given that the number of infants with septicaemia alone far exceeds the number with both necrotizing enterocolitis and septicaemia. In our experience, it is only a minority of infants with necrotizing enterocolitis who are frankly septicaemic, almost invariably with gram-negative organisms. We have never isolated anaerobes in blood cultures from preterm newborns, and for this reason it has been our policy for over 10 years, not to use metronidazole as a component of broad-spectrum antibacterial cover in infants with necrotizing enterocolitis.

\section{Comment}

In over 20 years of combined haematological and neonatal experience we have never seen a convincing case of neonatal haemolysis secondary to $\mathrm{T}$ antigen activation in either septicaemia or necrotizing enterocolitis. We do not believe that there is a necessity for low-titre anti-T donors.

\section{References}

1 Mollison PL, Engelfriet CP, Contreras M: Blood Transfusion in Clinical Medicine, ed 10. Oxford, Blackwell, 1997, pp 233-236.

2 Novak RW, Abbott AE, Klein RL: T-cryptantigen determination affects mortality in necrotising enterocolitis. Surg Gynecol Obstet 1993 176:368-370.

3 Heddle NM, Blajchman MA, Bodner N, et al: Absence of hemolysis of T-activated red cells following infusion of blood products. Commun Am Assoc Blood Banks, Atlanta 1977.

Dr. Elizabeth Letsky

Department of Haematology

Imperial College School of Medicine

Queen Charlotte's Hospital

Goldhawk Road (UK)

London W6 0XG

\section{Barbara Źupańska}

Question 1: In Poland, infants are not screened for polyagglutination and $\mathrm{T}$ activation. However, blood grouping is done using in parallel monoclonal antibodies and human sera. Hence, these is a good chance that polyagglutination is not missed. I am not aware of any serious haemolytic reactions due to polyagglutination in Poland, but nondiagnosed cases cannot be excluded.

Question 2: Before I am convinced that there is a need to screen for donors with anti$\mathrm{T}$ in low titre on a large scale, I would prefer to perform a multicentre study to evaluate the problem of polyagglutination and $\mathrm{T}$ activation. In Poland there are many newborns with infection, the mortality is high and the problem of polyagglutination might be underestimated; on the other hand, T activation may be very rare. I also hope that this International Forum will reach a consensus on what we mean by anti-T in low titre.

Question 3: Since severe haemolysis in patients with polyagglutination has been reported [1-3] it might be advisable for transfusion centres (maybe only some of them) to have a few donations of fresh frozen plasma with anti-T in low titre on their stock; the central registry could make such plasma available for the whole country. Patients with polyagglutination requiring red cells might be transfused, for the time being, with washed red blood cells, and patients requiring platelets might get platelets resuspended in saline.

\section{References}

1 Levene C, Sela R, Blat J, Friedlaender M, Manny L: Intracellular hemolysis and renal failure in a patient with $\mathrm{T}$ polyagglutination. Transfusion 1996;26:243-245.

2 Marshall LR, Barr AL, French NP, Lown JA, Knowles S: A fatal case of necrotizing enterocolitis in a neonate with polyagglutination of red blood cells. J Paediatr Child Health 1993;29:63-65.

3 Sigler E, Levene NA, Levene C, Shtalrid M: A rare mechanism for intravascular hemolysis. Am J Med 1992;92:113.

Prof. Barbara Źupańska, MD

Department of Serology

Institute of Haematology and

Blood Transfusion

Warsaw (Poland)

\section{Eleonore F. van Leeuwen}

$\mathrm{T}$ activation in vivo has been reported in association with severe infections caused by Streptococcus, Pneumococcus, Staphylococcus, Clostridium and other organisms. Usually, this phenomenon is transient. Anti-T is an IgM hemolytic and agglutinating antibody present in adult plasma but not in plasma of infants until about 6 months of age [1]. Therefore, neonates with $\mathrm{T}$ activation have little risk of hemolysis. Van Loghem et al. [2] published however the first case of intravascular hemolysis after transfusion in an infant attributed to $\mathrm{T}$ activation. Reports of similar cases followed. Special transfusion protocols by selecting donors with low-titre anti-T and restriction to plasma-poor blood products were advocated. In a prospective study, a low incidence of $\mathrm{T}$ activation in $0.6 \%$ of all neonatal intensive-care patients was observed but with a considerable frequency of $11 \%$ in patients with necrotizing enterocolitis [3]. Remarkably however, only 1 of the 72 patients with necrotizing enterocolitis showed massive hemolysis after transfusion. Moreover, T antigen testing before and shortly after transfusion was negative in this patient. Pretransfusion screening on $\mathrm{T}$ activation would not have prevented this phenomenon. There was no increase in the mortality rate between patients with necrotizing enterocolitis with or without $\mathrm{T}$ activation. These results indicate that special transfusion protocols for this patient group are disputable. We have recently performed a retrospective nationwide survey on this subject, inspired by this International Forum. A ques- 
tionnaire was sent to all ten regional neonatal intensive-care units in the Netherlands and the allied blood transfusion centers. A response was received from all centers. Yearly a total of about 2,200 patients are referred to these neonatal intensive-care units [4]. In none of the centers are the patients or selected groups of patients screened for $\mathrm{T}$ activation. During the last 10 years no massive intravascular hemolysis after transfusion has been recorded. In a few cases aggravation of existing hemolysis was observed after transfusion, but not distinguishable from the hemolysis due to the generally coexisting intravascular coagulation. None of the centers indicated that blood products of donors with anti-T in low titre were needed. Although the incidence of $\mathrm{T}$ activation and subsequent intravascular hemolysis was not thoroughly studied by this inquiry, the overall observation indicates no need for screening of patients for $\mathrm{T}$ activation of donors for anti- $\mathrm{T}$ titer. Also provision of special blood products for patients in neonatal intensive-care units appears not to be required.

\section{References}

1 Mollison PL, Engelfriet CP, Contreras M: Blood Transfusion in Clinical Medicine, ed. 9. Oxford, Blackwell Scientific Publications, 1993, p 310-316.

2 van Loghem JJ, van der Hart M, Land ME: Polyagglutinability of red cells as a cause of severe haemolytic transfusion reaction. Vox Sang 1955;5:125-128.

3 Williams RA, Brown EF, Hurst D, Franklin LC: Transfusion of infants with activation of erythrocyte T antigen. J Pediatr 1989;115:949953.

4 Kollee IAA, den Ouden AL, Drewes JG, Brouwers HAA, Verwey RA, Verloove-Vanhorick SP: Increased perinatal referral to regional centres of premature infants in the Netherlands: Comparison of 1983 and 1993.

Eleonore F. van Leeuwen

Blood Bank Midden Nederland

Rubenslaan 190

NL-3582 JJ Utrecht (The Netherlands)

\section{Carmen Martín-Vega}

Question 1: Anti-T in the plasma of normal donors has been implicated as a cause of severe haemolytic reactions in patients with T-activated red cells following transfusion with plasma or plasma products [1]. Although this is considered an infrequent phenomenon, recent studies [2, 3] have found a clear association between $\mathrm{T}$ activation and fatal cases of necrotizing enterocolitis. At our centre we only screen infants with necrotizing enterocolitis for polyagglutination and $\mathrm{T}$ activation, and in some cases of septicaemia if requested to do so by the Children's Hospital. We also perform the study in neonates who have received blood components and show intravascular hemolysis or unexplained failure to recover to the expected haemoglobin level.

Question 2: In cases of T activation [4], red cells are agglutinated by the anti-T that is present in the serum of all subjects although the $\mathrm{T}$ titre varies considerably in samples from different adults. In spite of some discrepancies, in my opinion, large blood transfusion centres with a great number of blood donors could be useful in screening donors for anti-T in low titre and in keeping the plasma frozen. Those donors should be registered to enable stocks of plasma with low-titre anti-T to be renewed. Because of the great variability of anti-T titre, it is only effective if it is done in blood transfusion centres where there are sufficient donors to make this process viable. The availability of low-titre antiT may be limited [5] but not impossible to be achieved.

Question 3: Infants with mild $\mathrm{T}$ antigen activation may be treated without difficulty, but some authors report cases with a fulminant course [1, 3]. I feel that the management of these cases should include a special protocol for administering washed red cells and washed platelets, and the blood bank should be able to provide plasma derivatives with anti-T in low titre if they are required [6].

In summary, screening for donors with anti- $\mathrm{T}$ in low titre should be performed in large centres with suitable facilities, and only low-titre anti- $T$ plasma or plasma derivatives need to be available since red cells and platelets only require reduction of plasma or washing.

\section{References}

1 van Loghem JJ, van der Hart M, Land ME: Polyagglutinability of red cells as a cause of severe haemolytic transfusion reaction. Vox Sang (original series) 1955;5:4-5.

2 Kirsten GF, Smith J, Pieper C, Bird A, Wessels $\mathrm{G}$, Riphagen S, Moore S: The necessity for Tcryptantigen activation screening in babies with necrotizing enterocolitis. S Afr Med J 1996;86:546-548.

3 Marshall LR, Barr AL, French NP, Lown JA, Knowles S: A fatal case of necrotizing enterocolitis with polyagglutination of red blood cells. J Paediatr Child Health 1993;29:63-65.

4 Mollison PL, Engelfriet CP, Contreras M: Blood Transfusion in Clinical Medicine. ed 9. Oxford, Blackwell Scientific Publications, 1993, pp 310-315.

5 Rodwell R, Tudehope DI: Screening for cryptantigen exposure and polyagglutination in neonates with suspected necrotizing enterocolitis. J Paediatr Child Health 1993;29:16-18.

6 Pisciotto PT, Luban N: Complications of neonatal transfusions; in Popovsky MA (ed): Transfusion Reactions. Bethesda, American Blood Bank Association, 1996.

Carmen Martín-Vega

Centre de Transfusió i Banc de teixits

Av. Vall d'Hebron 119-129

E- 08035 Barcelona (Spain)

\section{Tom Krusius}

After discussing the matter with experts in blood group serology and in neonatal care, we conclude that this problem has not been encountered during the last few decades. Probably it is much more uncommon at present than before, maybe due to improved care of neonates and the use of blood components containing little donor plasma. In Finland, we do not screen infants for polyagglutination. We feel that there is also no need to screen for donors with anti-T in low titer in order to provide special blood components for infants.

Tom Krusius, MD

Director, Laboratory Services

Finnish Red Cross Blood Transfusion Service

Kivihaantie 7

FIN-00310 Helsinki (Finland)

Tel. +358 58 011, Fax +358 5801329 